Original Research Paper

\title{
Isolation and Identification of Oral Cancer Stem Cells (CSC) within Commercially Available Cell Lines
}

\author{
${ }^{1}$ Robert Chauncey, ${ }^{1}$ Kai Hatch, ${ }^{1}$ Toni Jilka, ${ }^{1}$ Beau Seager and ${ }^{2}$ Karl Kingsley \\ ${ }^{I}$ Department of Clinical Sciences, School of Dental Medicine, \\ University of Nevada, Las Vegas - 1700 W. Charleston, Las Vegas, Nevada, 89106, USA \\ ${ }^{2}$ Department of Biomedical Sciences, School of Dental Medicine, \\ University of Nevada, Las Vegas - 1001 Shadow Lane, Las Vegas, Nevada, 89106, USA
}

Article history

Received: 21-05-2018

Revised: 25-05-2018

Accepted: 29-05-2018

Corresponding author:

Karl Kingsley

Department of Biomedical

Sciences, School of Dental

Medicine, University of Nevada,

Las Vegas-1001 Shadow Lane

Las Vegas, Nevada, 89106, USA

Tel: (702) 774-2623

Email: Karl.Kingsley@unlv.edu

\begin{abstract}
Previous studies have demonstrated some tumors develop or maintain a small sub-population of cells with stem cell-like properties. This Cancer Stem Cells (CSC) may exhibit differential properties that allow their escape from traditional radiation or chemotherapy treatments and may therefore be responsible for cancer recurrence. Few studies have explored this phenomenon among oral cancer cell lines, therefore the objective of this study was to examine multiple oral cancer cell lines to determine if any or all contained subpopulations of CSCs. Multiple commercially available Oral Squamous Carcinoma Cell (OSCC) lines were obtained for this study, including SCC15, SCC25 and CAL27. Cells were cultured for CSC screening and isolation. RNA was isolated from any potential CSC isolates for biomarker screening and verification. All OSCC lines examined developed adhesion-independent tumor spheres (AiTS), a characteristic phenotype of oral CSC. Each AiTS was manually isolated for separate, independent culture and analysis. RNA extracted from the AiTS revealed differential expression of specific CSC markers, including CD44, CD133, ABCG, CXCR6 and NANOG. These biomarkers were not observed in RNA extracted from the remaining nonCSC cell cultures. Although a previous study from this group successfully isolated AiTS from one cervical and one oral cancer cell line, this may be the first study to isolate CSC from multiple oral cancer cell lines and verify both cell-surface and intracellular CSC biomarkers. These results may suggest that many tumors and oral cancers could harbor AiTS and CSC and that screening for these sub-populations may provide guidance for treatment and therapy to improve oral cancer survival rates.
\end{abstract}

Keywords: Oral Cancer, Cancer Stem Cells, Biomarkers

\section{Introduction}

Previous studies have demonstrated some tumors develop or maintain a small sub-population of cells with stem cell-like properties (Chae and Kim, 2018; Tong et al., 2018; Czerwińska et al., 2018). These Cancer Stem Cells (CSCs) have been identified in many of the most common cancers, including lung, breast, prostate and colon tumors (Wang et al., 2018; Celià-Terrassa, 2018; Wade and Kyprianou, 2018; Hamzehzadeh et al., 2017). Although the presence of CSCs may help to explain the chemoresistance and subsequent recurrence of these cancers, recent evidence has also revealed the presence of CSCs in less prevalence tumors arising from the bladder, pancreas, thyroid and even tumors of the oral cavity (Li et al., 2017; Polireddy and Chen, 2016; Hardin et al., 2017; Baillie et al., 2017).

These cancer stem cells (CSC) may exhibit differential properties that allow their escape from traditional radiation or chemotherapy treatments and may therefore be responsible for cancer recurrence (Saini and Yang, 2017; Zhang et al., 2018). Most recently, evidence has suggested that specific therapies targeted towards the CSCs from specific tissue types may need to be developed to facilitate treatment and therapy (Ohnishi et al., 2017; Moharil et al., 2017; Bakhshinyan et al., 2018). As more information becomes available regarding the properties and mechanisms of CSC 
development in tumors, such as oral cancers, more effective treatments and therapies can be developed to improve survival and patient outcomes (Shang et al., 2018; Rodini et al., 2017; Wolmarans et al., 2017).

Despite the significance of these findings, few studies to date have explored this phenomenon among oral cancer cell lines, which could provide models for testing therapies and other treatment modalities (Felthaus et al., 2011; Wang et al., 2017; Kaseb et al., 2016). Based upon the paucity of evidence, the objective of this study was to examine multiple oral cancer cell lines to determine if any or all contained subpopulations of CSCs.

\section{Materials and Methods}

\section{Oral Cancer Cell Lines and Culture}

The cell lines used in this study were human oral cancer cell lines purchased from American Type Culture Collection (ATCC; Manassas, VA). These included SCC15 (CRL-1623), SCC25 (CRL-1628) and CAL27 (CRL-2095), which have all been characterized as oral squamous cell carcinomas (OSCC). Cells were cultured in Dulbecco's Modified Eagle's Medium (DMEM) with $4.0 \mathrm{mM}$ L-glutamine, modified with $3.7 \mathrm{~g} / \mathrm{L}$ sodium bicarbonate, $4.5 \mathrm{~g} / \mathrm{L}$ glucose, $110 \mathrm{mg} / \mathrm{L}$ sodium pyruvate and 10\% Fetal Bovine Serum (FBS). In addition, media was supplemented with antibiotics, which included Penicillin $(10,000$ units $/ \mathrm{mL})$ and Streptomycin $(10,000$ $\mathrm{ug} / \mathrm{mL}$ ) from HyClone (Logan, UT). All cultures were maintained in a humidified cell culture incubator at 37C with 5\% CO2 and all experiments were performed in an approved Biosafety Level -2 (BSL2) cabinet, as previously described (Osafi et al., 2014; Moody et al., 2012).

\section{Microscopy and AiTS Isolation}

Microscopy was accomplished using an Axiovert 40 inverted microscopy from Zeiss (Gottingen, Germany) and images were captured at 200X magnification using a PowerShot G6 digital camera from Canon (Tokyo, Japan) and processed using Adobe Photoshop (San Jose, $\mathrm{CA})$. Isolation of potential $\mathrm{CSC}$ isolates was accomplished by culturing the OSCC cell lines to $100 \%$ confluence and allowing subsequent overgrowth. Adhesion-independent tumor spheres (AiTS) were isolated manually using micropipettes from the Z-plane (upwards) without firm adhesion to the deposited extracellular matrix (ECM) or cell-cell X- and Y-plane attachments. Multiple passages of each cell line were required to obtain sufficient cells for subsequent analysis.

\section{RNA Isolation and Analysis}

RNA was isolated from the OSCC cell cultures and the AiTS isolates from each of the experimental lines using the Total RNA Isolation Reagent from ABgene (Surrey, UK) according to the procedure recommended by the manufacturer, as previously described (Osafi et al., 2014; Moody et al., 2012).

Approximately $1.5 \times 10^{7}$ cells from each cell culture and AiTS isolate were processed and the RNA concentration were determined using UV spectroscopy. Quantity and quality of RNA were determined using the absorbance of diluted RNA samples (1:50 dilution) suspended in nuclease-free water, $\mathrm{pH}$ 7.0) measured at 260 and $280 \mathrm{~nm}$. RNA purity was determined using the ratio of A260:A280, which should be 1.65 or higher for RT-PCR analysis. Concentration was determined using A260 multiplied by the extinction coefficient (RNA in nuclease free water $=40$ ) and the dilution factor $(50)$ :

RNA standard: A260 (absorbance) $=0.75$

Concentration $=40$ (extinction factor) $\times 50$ (dilution factor) $\times 0.75=1,500 \mathrm{ug} / \mathrm{mL} \mathrm{RNA}$

\section{Reverse Transcription Polymerase Chain Reaction (RT-PCR) Screening}

To determine the expression (or lack of expression) of CSC-specific mRNA markers, RT-PCR was used to screen total RNA isolated from the OSCC cell lines and AiTS. Screening was accomplishing using the ABgene Reverse-iTOne-Step RT-PCR Kit and Mastercycler gradient thermocycler from Eppendorf (Hamburg, Germany) with the following primers, synthesized by SeqWright (Houston, TX).

Positive Control Human mRNA standards:

c-myc FORWARD:

TCCAGCTTGTACCTGCAGGATCTGA; 25 nt, 52\% GC, Tm 72C

c-myc REVERSE:

CCTCCAGCAGAAGGTGATCCAGACT; 25 nt, 56\% GC, Tm 72C

Optimal Tm: Lower annealing temperature $-5 \mathrm{C}=68 \mathrm{C}$

Glyceraldehyde-3-phosphate dehydrogenase (GAPDH): GAPDH FORWARD:

ATCTTCCAGGAGCGAGATCC; 20 nt, 55\% GC, 66C GAPDH REVERSE: ACCACTGACACGTTGGCAGT; $20 \mathrm{nt}, 55 \% \mathrm{GC}, 70 \mathrm{C}$

Optimal Tm: Lower annealing temperature $-5 \mathrm{C}=61 \mathrm{C}$

CSC Cell Surface Markers:

CD44 FORWARD:

GAAAGGCATCTTATGGATGTGC; 22 nt, 45\% GC, $64 \mathrm{C}$

CD44 REVERSE: CTGTAGTGAAACACAACACC; 20 nt, $45 \%$ GC, $61 \mathrm{C}$

Optimal Tm: Lower annealing temperature $-5 \mathrm{C}=56 \mathrm{C}$

CD133 FORWARD: 
CTCATGCTTGAGAGATCAGGC; 21nt, 52\% GC, 65C CD133 REVERSE: CGTTGAGGAAGATGTGCACC; $20 \mathrm{nt}, 55 \% \mathrm{GC}, 66 \mathrm{C}$

Optimal Tm: Lower annealing temperature $-5 \mathrm{C}=60 \mathrm{C}$

CSC Intracellular Markers:

ABCG-2 FORWARD:

AGTTCCATGGCACTGGCCATA; 21 nt, 52\% GC, 69C

ABCG-2 REVERSE:

CAGGTAGGCAATTGTGAAGG; 21 nt, 485 GC, 65C

Optimal Tm: Lower annealing temperature $-5 \mathrm{C}=60 \mathrm{C}$

NANOG FORWARD:

GCTGAGATGCCTCACACGGAG; 21 nt，62\% GC, $71 \mathrm{C}$

NANOG REVERSE:

TCTGTTTCTTGACTGGGACCTTGTC; 25 nt, 48\%, 69C

Optimal Tm: Lower annealing temperature $-5 \mathrm{C}=64 \mathrm{C}$

\section{CXCR6 FORWARD:}

ATGGCAATGTCTTTAATCTCGACAA; 25 nt, 36\% GC, 64C

CXCR6 REVERSE:

TGAAAGCTGGTCATGGCATAGTATT; 25 nt, 40\% GC, 66C

Optimal Tm: Lower annealing temperature $-5 \mathrm{C}=59 \mathrm{C}$

In brief, mRNA positive control standards were used to establish the minimum threshold cycle (CT) and saturation cycle (CS) for RT-PCR and to confirm the successful isolation of RNA from each isolate and cell line. Signal detection above background was observed above ten (10) cycles or CT10 with saturation observed at forty (40) cycles or CS40. Using this information, RTPCR was performed at thirty (30) cycles, above the threshold detection limit but below the saturation point.

In brief, one (1) ug of template (total) RNA was used for each screening reaction, with reverse transcription set for $30 \mathrm{~min}$ at $47 \mathrm{C}$, followed by denaturation for two (2) minutes at 94C. Thirty (30) amplification cycles were performed, using the template of denaturation at $94 \mathrm{C}$ for twenty (20) seconds, annealing at the optimal annealing temperature or $\mathrm{Tm}$ (primer specific) for thirty (30) seconds and extension for an additional five (5) minutes. Products were subsequently separated using gel electrophoresis using Reliant NuSieve Agarose gels and visualized by UV illumination of ethidium bromidestained gels and captured using a Gel Logic 100 Imaging System and 1D Image Analysis Software from Kodak (Rochester, NY).

\section{Statistical Analysis}

Differences in RNA concentration and purity between OSCC cell lines and the corresponding AiTS isolates were determined using two-tailed t-tests, which are appropriate for use with parametric data. Statistical significance was set at an alpha level of $\mathrm{a}=0.05$ and descriptive statistics were provided along with the appropriate $\mathrm{p}$-value.

\section{Results}

Oral Squamous Cell Carcinoma (OSCC) cell lines SCC25, SCC15 and CAL27 were cultured and passaged to screen for the presence of potential oral Cancer Stem Cells (CSC) (Fig. 1). These experiments demonstrated that each cell line produced adhesion-independent tumor spheres (AiTS) that grew into the Z-plane after the cell line becoming confluent. Micropipette isolation of these AiTS for SCC25 (Fig. 1A and 1B), SCC15 (Fig. 1C and 1D) and CAL27 (Fig. 1E and 1F) revealed these microstructures had developed sufficient intercellular cell-cell adhesion (Fig. 1A, 1C, 1E) to maintain this configuration during isolation and manual micropipette transfer (Fig. 1B, 1D, 1F).

RNA was isolated from each cell line and the AiTS separated from each corresponding cell line (Table 1). In brief, the RNA derived from the OSCC cell lines had an overall average concentration of $370.7 \mathrm{ng} / \mathrm{uL}$ with a range from 311.4- 412.6 ng/uL, while the RNA isolated from the AiTS had a lower overall average concentration of $256.3 \mathrm{ng} / \mathrm{uL}$ that ranged from 243.3 to $266.3 \mathrm{ng} / \mathrm{uL}$. The purity of RNA isolated from the OSCC cell lines averaged 1.73 and ranged between 1.68 and 1.77, while the AiTS had an overall higher average purity of 1.88 that ranged from 1.84 to 1.91 . These differences between each OSCC cell line and the corresponding AiTS isolate were statistically significant, as were the differences between the combined averages of the OSCC when compared with the averages of the AiTS isolates $(\mathrm{p}<0.01)$.

Table 1: RNA Isolation and Analysis

\begin{tabular}{llll}
\hline & $\begin{array}{l}\text { RNA } \\
\text { concentration }\end{array}$ & $\begin{array}{l}\text { RNA purity } \\
(\text { A260:A280) }\end{array}$ & $\begin{array}{l}\text { Statistical } \\
\text { analysis }\end{array}$ \\
\hline SCC15 & $311.4 \mathrm{ng} / \mathrm{uL}$ & 1.73 & Two-tailed t-test \\
SCC15-AiTS & $266.3 \mathrm{ng} / \mathrm{uL}$ & 1.88 & $\begin{array}{l}\text { Two-tailed t-test } \\
\text { Two-t }\end{array}$ \\
SCC25 & $412.6 \mathrm{ng} / \mathrm{uL}$ & 1.68 & $p<0.01$ \\
SCC25-AiTS & $243.3 \mathrm{ng} / \mathrm{uL}$ & 1.91 & Two-tailed t-test \\
CAL27 & $388.2 \mathrm{ng} / \mathrm{uL}$ & 1.77 & $p<0.01$ \\
CAL27-AiTS & $259.2 \mathrm{ng} / \mathrm{uL}$ & 1.84 & $p<0.01$ \\
OSCC average & $370.7 \mathrm{ng} / \mathrm{uL}$ & 1.73 & \\
AiTS average & $256.3 \mathrm{ng} / \mathrm{uL}$ & 1.88 & \\
OSCC range & $311.4-412.6 \mathrm{ng} / \mathrm{uL}$ & $1.68-1.77$ & \\
AiTS range & $243.3-266.3 \mathrm{ng} / \mathrm{uL}$ & $1.84-1.91$ & \\
\hline
\end{tabular}




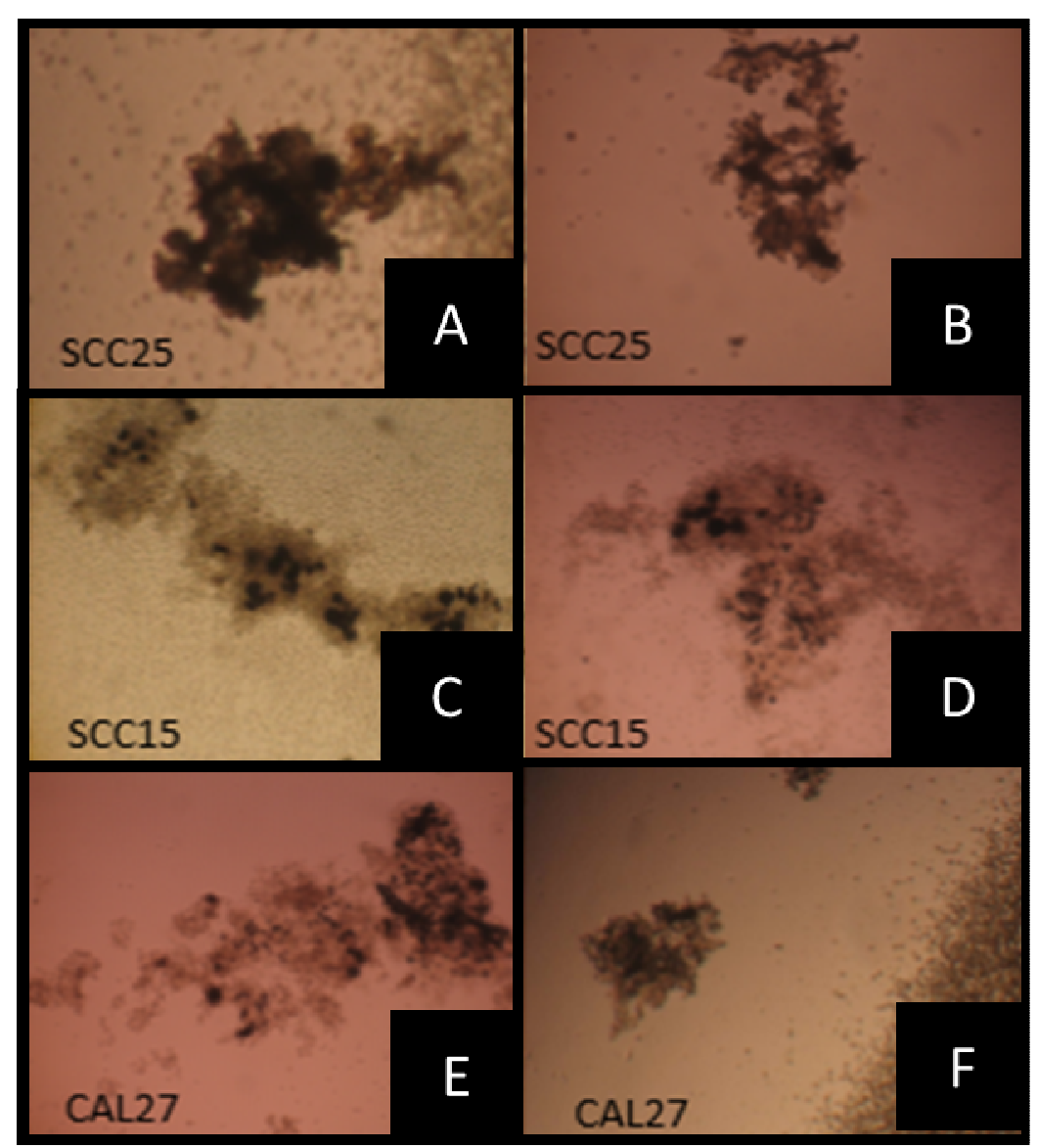

Fig. 1: Isolation of Adhesion-Independent Tumor Spheres (Potential Cancer Stem Cells) from Oral Cancer Cell Lines. Commercial oral cancer cell lines developed adhesion-independent tumor spheres or aggregates, which were isolated using micropipettes and subsequently documented using photo microscopy (A-F). Several AiTS were isolated for SCC25 (A, B), SCC15 (C, D) and CAL27 (E, F), which were then cultured for RNA isolation. Most AiTS identified for transfer (A, C, E) retained cell-cell adhesion during and post transfer $(\mathrm{B}, \mathrm{D}, \mathrm{F})$.

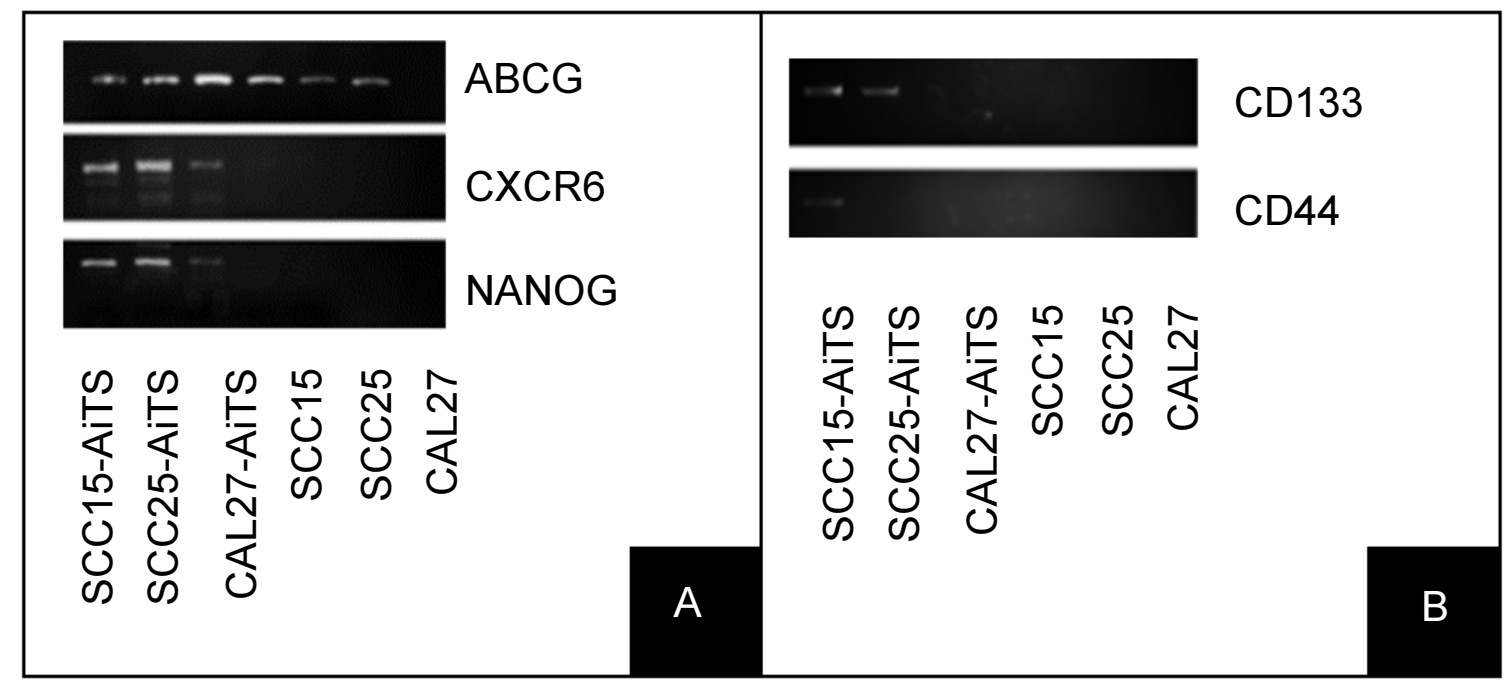

Fig. 2: RT-PCR screening of RNA isolates. RNA from OSCC and the corresponding AiTS was screened using RT-PCR and primers specific for both cell surface (CD44, CD133) and intracellular markers (NANOG, ABCG, CXCR6) 
To determine whether any of the AiTS isolates from the OSCC cell lines expressed any biomarkers characteristic of cancer stem cells, the RNA isolated from each cell line was screened for mRNA using both intracellular and cell-surface targets (Fig. 2). This screening revealed that mRNA from the OSCC cell lines did not express mRNA for the intracellular markers NANOG or CXCR6, with variable low-level expression of ABCG (Fig. 2A). In contrast, all the AiTS expressed mRNA for CXR6 and NANOG, as well as ABCG.

In addition, RNA was also screened for cell surface markers CD44 and CD133 (Fig. 2B). This analysis revealed no evident mRNA expression among the OSCC cell lines, with weak expression among two of the three AiTS isolates (SCC15 and SCC25).

\section{Discussion}

Few studies to date have assessed the potential for subpopulations of CSC to exist among oral cancer cell lines, which could provide models for testing therapies and other treatment modalities (Felthaus et al., 2011; Wang et al., 2017; Kaseb et al., 2016). Based upon the paucity of evidence, the objective of this study was to examine multiple oral cancer cell lines to determine if any or all contained subpopulations of CSCs. The results of this pilot study revealed that each OSCC cell line harbored a subpopulation of adhesion-independent tumor spheres that exhibited both intracellular and some cellsurface biomarkers that indicate the presence of CSCs.

\section{Conclusion}

These findings are critically important as more evidence accumulates that suggest subpopulations of CSC may be critical factors in determining the treatment strategy and overall prognosis in oral cancer patients (Ravindran et al., 2015; Mohanta et al., 2017; He et al., 2014). In fact, new evidence suggests that metastatic potential and invasiveness may be heavily dependent upon these CSC subpopulations, therefore more information regarding their properties and survival in well-characterized systems will be critical to further our understanding of these phenomenon (Rodrigues et al., 2018; Shah et al., 2018; Chen et al., 2018). As more studies evaluate the role of CSC in oral cancer, more accurate and predictive models of therapy and prognosis will be needed to more effectively treat and manage patient care (Teixeira and Corrêa, 2018; Castilho et al., 2017).

\section{Acknowledgement}

Dr. Kingsley would like to thank the Office of Research at the University of Nevada, Las Vegas, School of Dental Medicine and the Graduate and Professional Student Association at the University of Nevada, Las Vegas for research funds to complete this pilot study.

\section{Author Contributions}

Robert Chauncey and Kai Hatch: Were responsible for the sample processing and data collection.

Toni Jilka, Beau Seager and Karl Kingsley: Were responsible for the data analysis and manuscript preparation. All authors have read and approved this manuscript.

\section{Conflicts of Interest}

The authors declare there are no conflicts of interest to report.

\section{References}

Baillie, R., S.T. Tan and T. Itinteang, 2017. Cancer stem cells in oral cavity squamous cell carcinoma: A Review. Front Oncol., 7: 112. DOI: $10.3389 /$ fonc. 2017.00112

Bakhshinyan, D., A.A. Adile, M.A. Qazi, M. Singh and M.M. Kameda-Smith, 2018. Introduction to cancer stem cells: Past, present and future. Methods Mol. Biol., 1692: 1-16. DOI: 10.1007/978-1-4939-7401-6_1

Castilho, R.M., C.H. Squarize and L.O. Almeida, 2017. Epigenetic modifications and head and neck cancer: Implications for tumor progression and resistance to therapy. Int. J. Mol. Sci., 18: 1506.

DOI: $10.3390 /$ ijms 18071506

Celià-Terrassa, T., 2018. Mammary stem cells and breast cancer stem cells: Molecular connections and clinical implications. Biomedicines, 6: 50. DOI: 10.3390/biomedicines6020050

Chae, Y.C. and J.H. Kim, 2018. Cancer stem cell metabolism: Target for cancer therapy. BMB Rep. PMID: 29764565

Chen, L., Y.C. Li, L. Wu, G.T. Yu and W.F. Zhang et al., 2018. TRAF6 regulates tumour metastasis through EMT and CSC phenotypes in head and neck squamous cell carcinoma. J. Cell Mol. Med., 22: 1337-1349. DOI: $10.1111 / \mathrm{jcmm} .13439$

Czerwińska, P., S. Mazurek and M. Wiznerowicz, 2018. Application of induced pluripotency in cancer studies. Rep. Pract. Oncol. Radiother., 23: 207-214. DOI: 10.1016/j.rpor.2018.04.005.

Felthaus, O., T. Ettl, M. Gosau, O. Driemel and G. Brockhoff et al., 2011. Cancer stem cell-like cells from a single cell of oral squamous carcinoma cell lines. Biochem. Biophys. Res. Commun., 407: 28-33. DOI: 10.1016/j.bbrc.2011.02.084

Hamzehzadeh, L., M. Yousefi and S.H. Ghaffari, 2017. Colorectal cancer screening: A comprehensive review to recent non-invasive methods. Int. J. Hematol. Oncol. Stem. Cell Res., 11: 250-261. 
Hardin, H., R. Zhang, H. Helein, D. Buehler and Z. Guo et al., 2017. The evolving concept of cancer stem-like cells in thyroid cancer and other solid tumors. Lab Invest., 97: 1142-1151.

DOI: 10.1038/labinvest.2017.41

He, K.F., L. Zhang, C.F. Huang, S.R. Ma and Y.F. Wang et al., 2014. CD163+ tumor-associated macrophages correlated with poor prognosis and cancer stem cells in oral squamous cell carcinoma. Biomed. Res. Int. DOI: 10.1155/2014/838632

Kaseb, H.O., H. Fohrer-Ting, D.W. Lewis, E. Lagasse and S.M. Gollin, 2016. Identification, expansion and characterization of cancer cells with stem cell properties from head and neck squamous cell carcinomas. Exp. Cell Res., 348: 75-86. DOI: 10.1016/j.yexcr.2016.09.003

Li, Y., K. Lin, Z. Yang, N. Han and X. Quan et al., 2017. Bladder cancer stem cells: Clonal origin and therapeutic perspectives. Oncotarget, 8: 66668-66679. DOI: 10.18632/oncotarget.19112

Mohanta, S., G. Siddappa, S.G. Valiyaveedan, R. Dodda and T. Ramanjanappa et al., 2017. Cancer stem cell markers in patterning differentiation and in prognosis of oral squamous cell carcinoma. Tumour Biol., 39: 010428317703656.

DOI: 10.1177/1010428317703656.PMID: 28631562

Moharil, R.B., A. Dive, S. Khandekar and A. Bodhade, 2017. Cancer stem cells: An insight. J. Oral. Maxillofac. Pathol., 21: 463.

DOI: 10.4103 /jomfp.JOMFP_132_16

Moody, M., O. Le, M. Rickert, J. Manuele and S. Chang et al., 2012. Folic acid supplementation increases survival and modulates high risk HPVinduced phenotypes in oral squamous cell carcinoma cells and correlates with p53 mRNA transcriptional down-regulation. Cancer Cell Int., 12: 10. DOI: $10.1186 / 1475-2867-12-10$

Ohnishi, Y., H. Yasui, M. Nozaki and M. Nakajima, 2017. Molecularly-targeted therapy for the oral cancer stem cells. Jpn. Dent. Sci. Rev., 54: 88-103. DOI: $10.1016 /$ j.jdsr.2017.11.001

Osafi, J., A. Hejazi, D.D. Stutz, M.A. Keiserman and C.J. Bergman, 2014. Differential effects of 1,25dihydroxyvitamin $\mathrm{D}_{3}$ on oral squamous cell carcinomas in vitro. J. Diet. Suppl., 11: 145-54. DOI: $10.3109 / 19390211.2013 .859209$

Polireddy, K. and Q. Chen, 2016. Cancer of the pancreas: Molecular pathways and current advancement in treatment. J. Cancer, 7: 1497-514. DOI: $10.7150 /$ jca. 14922

Ravindran, G., S.S. Sawant, A. Hague, K. Kingsley and H. Devaraj, 2015. Association of differential $\beta$ catenin expression with Oct-4 and Nanog in oral squamous cell carcinoma and their correlation with clinicopathological factors and prognosis. Head Neck., 37: 982-93. DOI: 10.1002/hed.23699
Rodini, C.O., N.M. Lopes, V.S. Lara and I.C. Mackenzie, 2017. Oral cancer stem cells-properties and consequences. J. Appl. Oral. Sci., 25: 708-715. DOI: 10.1590/1678-7757-2016-0665

Rodrigues, M.F.S.D., F.C.A. Xavier, N.P. Andrade, C. Lopes and L. Miguita Luiz et al., 2018. Prognostic implications of CD44, NANOG, OCT4 and BMI1 expression in tongue squamous cell carcinoma. Head Neck. DOI: 10.1002/hed.25158

Saini, N. and X. Yang, 2017. Metformin as an anticancer agent: Actions and mechanisms targeting cancer stem cells. Acta Biochim. Biophys. Sin., 50: 133-143. DOI: 10.1093/abbs/gmx106

Shah, K., S. Patel, B. Modi, F. Shah and R. Rawal, 2018. Uncovering the potential of CD44v/SYNE1/miR34a axis in salivary fluids of oral cancer patients. J. Oral Pathol. Med., 47: 345-352. DOI: 10.1111/jop. 12678

Shang, W., Q. Zhang, Y. Huang, R. Shanti and F. Alawi et al., 2018. Cellular plasticity-targeted therapy in head and neck cancers. J. Dent Res., 97: 654-664. DOI: $10.1177 / 0022034518756351$

Teixeira, M.G. and L. Corrêa, 2018. Quality assessment of prognostic studies using cancer stem cell markers in oral squamous cell carcinoma. Appl. Immunohistochem. Mol. Morphol., 26: e61-e69. DOI: $10.1097 /$ PAI.0000000000000569

Tong, M., Z. Deng, X. Zhang, B. He and M. Yang et al., 2018. New insights from the widening homogeneity perspective to target intratumor heterogeneity. Cancer Commun., 38: 17. DOI: $10.1186 / \mathrm{s} 40880-018-0287-y$

Wade, C.A. and N. Kyprianou, 2018. Profiling prostate cancer therapeutic resistance. Int. J. Sci., 19: 904. DOI: $10.3390 /$ ijms 19030904

Wang, J., L. Li, L. Gao, C. Guan and K. Su et al., 2017. Identification of differentially expressed genes in oral squamous cell carcinoma TCA8113 cells. Oncol. Lett., 14: 7055-7068. DOI: $10.3892 / \mathrm{ol} .2017 .7108$

Wang, Y., M. Jiang, C. Du, Y. Yu and Y. Liu et al., 2018. Utilization of lung cancer cell lines for the study of lung cancer stem cells. Oncol. Lett., 15: 6791-6798. DOI: 10.3892/ol.2018.8265

Wolmarans, E., S.C. Boy, S. Nel, A.E. Mercier and M.S. Pepper, 2017. Cancer stem cells in head and neck carcinomas: Identification and Possible Therapeutic Implications. Adv. Exp. Med. Biol. DOI: $10.1007 / 55842017116$

Zhang, D., D.G. Tang and K. Rycaj, 2018. Cancer stem cells: Regulation programs, immunological properties and immunotherapy. Semin. Cancer Biol. DOI: 10.1016/j.semcancer.2018.05.001 